\title{
Peningkatan kecerahan dan daya rekat warna pada produk gerabah batik
}

\author{
Edi Eskak,$^{*}$ Irfaina Rohana Salma, ${ }^{1}$ Hadi Sumarto ${ }^{1}$ \\ ${ }^{I}$ Balai Besar Kerajinan dan Batik, Badan Penelitian dan Pengembangan Industri, Kementerian Perindustrian RI, Yogyakarta, Indonesia
}

\begin{abstract}
Application of batik techniques for decoration making on pottery products results in unique decorative motifs. Decorative motifs are formed by the process of color blocking using a substance called 'malam' (batik wax) on the surface of pottery, but the resulted colors are less bright. The adhesiveness of colors on the surface of pottery are also less strong. The purpose of this study is to optimize materials and batik pottery production process to improve the brightness and adhesion of the colors. Methods used are: (1) selection of pottery, (2) designing of motifs, (3) penyantingan/batik making, (4) staining (5) pelorodan / wax cleaning, (6) finishing, and (7) testing of fastness. The results show that the use of colorants rapid and naphthol produces brighter colors. The increasing color brightness is achieved with the initial step of selecting light colored pottery and completed with a final coating of transparent paint. Tests were performed on color resistancy to rubbing and midday direct light, with score ranging 1 - 5. The testing color resistancy to dry and wet rubbing results in a score of 3-4 (good enough). Color resistancy to direct midday light gets 4 (good). Brightness and fastness (strong adhesion) to transparently painted colors obtain a score of 5 (very good).
\end{abstract}

Keywords: Increase of brightness, color adhesion, batik pottery.

\begin{abstract}
Abstrak
Penerapan teknik batik untuk pembuatan dekorasi pada produk gerabah, menghasilkan motif hias yang unik. Motif hias terbentuk dari proses penghalangan warna oleh torehan-torehan tapak malam (lilin batik) pada permukaan gerabah, namun warna-warna yang dihasilkan kurang cerah. Daya rekat warna pada permukaan gerabah juga kurang kuat. Tujuan penelitian ini adalah melakukan optimalisasi bahan dan proses pembuatan gerabah batik untuk meningkatkan kecerahan dan daya rekat warnanya. Metode yang digunakan yaitu: (1) Pemilihan gerabah, (2) Pembuatan desain motif, (3) Penyantingan/pembatikan, (4) Pewarnaan (5) Pelorodan/pembersihan lilin, (6) Finishing, dan (7) Pengujian ketahanan luntur. Hasil penelitian menunjukkan bahwa penggunaan pewarna rapid dan naphthol menghasilkan warna yang lebih cerah.Peningkatan kecerahan warna ini dilakukan dengan langkah awal berupa pemilihan gerabah yang berwarna muda serta dilakukan pelapisan akhir cat transparan. Pengujian dilakukan terhadap ketahanan luntur warna terhadap gosok dan cahaya tengah hari, dengan skor penilaian angka $1-5$. Hasil pengujian ketahanan luntur warna terhadap gosokan kering dan basah dengan memperoleh nilai 3-4 (cukup baik). Ketahanan luntur warna terhadap cahaya terang hari memperoleh angka 4 (baik). Kecerahan dan ketahanan luntur (daya rekat kuat) terhadap warna yang dilapisi cat transparan memperoleh nilai 5 (sangat baik).
\end{abstract}

Kata kunci: peningkatan kecerahan, daya rekat warna, gerabah batik.

\section{Pendahuluan}

Industri kerajinan gerabah tersebar hampir di semua wilayah Nusantara, karena merupakan kegiatan industri tradisional penyedia peralatan masak dan peralatan saji pada masa lalu. Gerabah adalah suatu kerajinan dengan media tanah liat yang dibentuk basah, dikeringkan dan dibakar secara tradisional (Astuti,
2008:9). Gerabah diperkirakan telah ada sejak masa pra sejarah, tepatnya setelah manusia hidup menetap dan mulai bercocok tanam. Semula produk gerabah berupa perkakas alat-alat yang berguna membantu kehidupan manusia (Rosari, 2013:72). Wujud produk gerabah tradisional antara lain anglo, kendi, cobek, kendil, kreneng, genthong, paso, genteng, tempat sesaji, dan mainan anak tradisional.

\footnotetext{
* Koresponden penulis e-mail : eskakedi@gmail.com
} 
Seiring perkembangan zaman, gerabah mengalami perubahan fungsi awalnya, yaitu semula sebagai peralatan rumah tangga fungsional, kini sebagai benda hias, benda hias fungsional, dan benda antik. Perubahan ini terjadi karena tugas gerabah tradisional telah banyak tergantikan dengan produk dari bahanbahan lain yang lebih praktis. Kendi misalnya yang semula berfungsi sebagai teko tempat air minum, kini fungsinya telah tergantikan oleh teko dari bahan aluminium, stainless steel, email, dan plastik. Gerabah sebagai alat rumah tangga mulai tergusur fungsinya oleh kehadiran bahan lain yang lebih praktis. Sebagai contoh, tempat air minum kendi kemudian menjadi barang usang, yang kemudian menjadi barang antik sebagai koleksi seni. Kecenderungan ini kemudian disikapi oleh perajin kreatif untuk membuat gerabah hias dengan membuat vas bunga, patung, lampu hias, relief, dan produk-produk kreatif lainnya. Pada umumnya gerabah hias ditambahi proses finishing untuk memperindah penampilannya, salah satu cara memberi tambahan dekorasi yang bisa diterapkan adalah teknik batik. Teknik dekorasi batik awalnya adalah upaya menghias untuk memperindah kain. Dekorasi batik sebagai mana pada media kain adalah menggunakan lilin atau malam sebagai perintang warna dalam pencelupan zat warna (Eskak, 2013:1, Suminto, 2015:23).

Penerapan teknik batik pada gerabah adalah salah satu eksplorasi teknik seni untuk mendapatkan produk baru yang kreatif. Produk gerabah batik IKM (Industri Kecil dan Menegah) sebenarnya mendapatkan respon pasar yang bagus, namun banyak yang urung membeli karena kualitas warna yang kurang cerah dan warna kurang merekat kuat pada permukaan gerabah. Oleh karena itu dilakukan penelitian peningkatan kecerahan dan daya rekat warna pada gerabah batik.Hasil pewarnaan yang bagus akan menimbulkan minat orang atau konsumen untuk membelinya, sehingga dapat meningkatkan nilai penjualan.Tujuan penelitian ini adalah melakukan optimalisasi bahan dan proses pembuatan gerabah batik untuk meningkatkan kecerahan dan daya rekat warnanya.

\section{Bahan dan Metode}

Pelaksanaan kegiatan ini memerlukan bahan-bahan yaitu gerabah polosan, malam (lilin batik), naphtol, rapid, remasol, soda abu (Na2CO3), cat bening. Sedangkan alat yang digunakan yaitu kompor listrik batik, canting, kuas ijuk, pensil, pensil warna, kapur, kompor lorod, gas elpiji, bak lorod stainless, air tawar, semprotan air panas, bak plastik, sarung tangan karet, cutter, kuas, ember, galah lorod, sarung tangan tahan panas, kain lap, dan kompor lorod.

Prosedur kerja yang dilakukan adalah: (1) pemilihan gerabah, (2) pembuatan desain motif, (3) penyantingan/pembatikan, (4) pewarnaan (5) pelorodan/pembersihan lilin, (6) finishing, dan (7) pengujian ketahanan luntur. Prosedur kerja ini masih menggunakan prosedur kerja yang dilakukan dalam penelitihan terdahulu (Sumarto, dkk., 2010:16), tetapi dilakukan usaha optimalisasi dengan menginventarisir permasalahan kegagalan yang ada kemudian dicarikan solusi pemecahannya sehingga dihasilkan pembuatan produk gerabah batik dengan kualitas yang lebih bagus.

Optimalisasi proses pembuatan gerabah batik dilakukan dengan langkah-langkah sebagai berikut:

Pemilihan gerabah polosan. Pemilihan gerabah polosan yang akan dibatik dilakukan dengan teliti agar memudahkan dalam proses pendekorasian dengan teknik batik. Kriteria gerabah bagus adalah permukaan halus, berwarna cerah/muda, dan tidak retak. Gerabah yang cacat retak maka retakan tersebut akan semakin besar saat proses pelorodan. Cacat retak bila tidak sampai pecah dapat diperbaiki dengan pendempulan tepung serbuk gerabah yang lembut (dari sisa amplasan gerabah) yang dicampur lem.

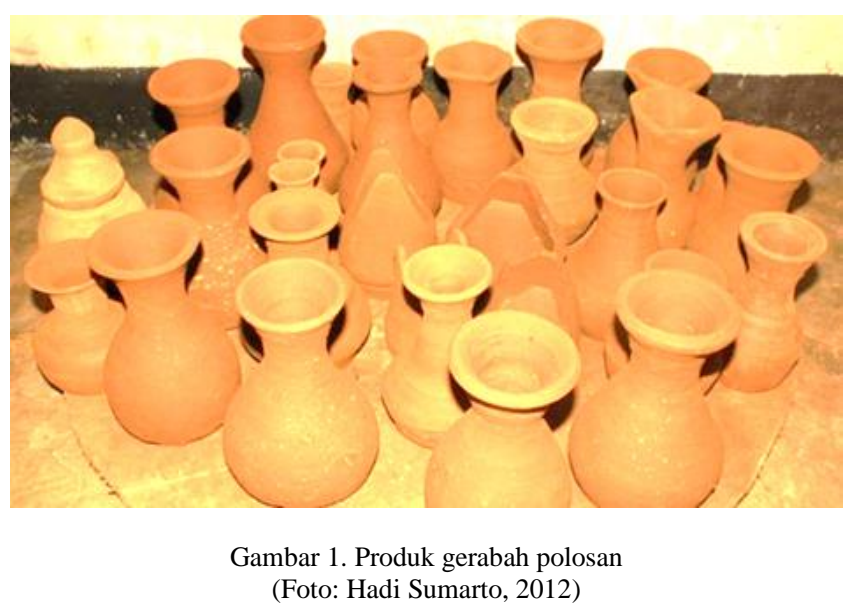

Gerabah yang dipilih sebaiknya yang dibakar dengan kematangan sedang. Jika pembakaran kurang matang, maka terjadi pori-pori besar. Hal ini akan berpengaruh dalam proses pewarnaan, yaitu bahan pewarna banyak terserap serta terjadi pengikisan warna pada saat pelorodan, karena ada tanah liat yang ikut luruh. Jika pembakarannya terlalu tinggi mengakibatkan pori-pori mengecil sehingga penyerapan terhadap bahan pewarna batik kurang baik. Jadi gerabah yang akan diproses batik sebaiknya gerabah yang tingkat kematangannya sedang. Gerabah 
polosan yang memenuhi kriteria bagus untuk diproses menjadi gerabah batik dapat dilihat dalam Gambar 1 .

Pembuatan desain motif. Desain motif yang diterapkan adalah motif hasil dari stilasi berbagai macam tumbuhan, binatang, benda, yang dikreasikan dalam komposisi motif geometris maupun motif dinamis (semen). Pemindahan desain motif ke permukaan gerabah menggunakan pensil, pensil warna, dan kapur tulis. Sebelum digambari motif, gerabah dibersihkan dari debu dengan cara dicuci dengan air bersih, sehingga bila diraba terasa kesat atau tidak licin. Penggoresan pensil maupun kapur jangan terlalu kuat sehingga menghasilkan garis yang tebal, tetapi garis tipis dan bersih. Bila ada kesalahan garis, dapat dibersihkan dengan diusap kain lap yang telah dibasahi air. Garis-garis tipis inilah yang nantinya digunakan sebagai penuntun dalam penyanting dengan lelehan malam (lilin batik) panas. Pemindahan motif dapat dilakukan dengan cara gambar langsung pada permukaan gerabah, maupun dengan cara menggunakan cetakan pola. Cara yang lebih praktis dan efektif adalah cara penggambaran langsung pada gerabah.
Penyantingan/Pembatikan. Setelah desain motif dipindahkan ke permukaan gerabah, maka langkah berikutnya adalah menorehkan malam (lilin batik) panas dengan cara dituliskan membentuk garis-garis motif yang ada. Tujuan penyantingan ini adalah pemberian lapisan lilin pada bidang gerabah untuk merintangi warna meresap pada permukaannya. Kontras antara permukaan yang terintangi malam, dan permukaan yang terwarnai inilah yang akan menghasilkan motif. Bahan yang digunakan adalah malam (lilin batik) yang biasanya dipakai untuk membuat batik pada kain. Alat yang digunakan adalah kompor listrik untuk batik, wajan batik, canting, serabut sapu ijuk, dan kuas kecil.

Pewarnaan. Setelah motif pada gerabah selesai dicanting, maka langkah selanjutnya adalah pewarnaan. Pewarnaan dapat dilakukan dengan cara dicelup atau diguyur dan dikuas atau di-colet. Pewarna yang digunakan adalah pewarna yang biasa digunakan untuk batik kain, yaitu rapid, naphtol, dan remasol.

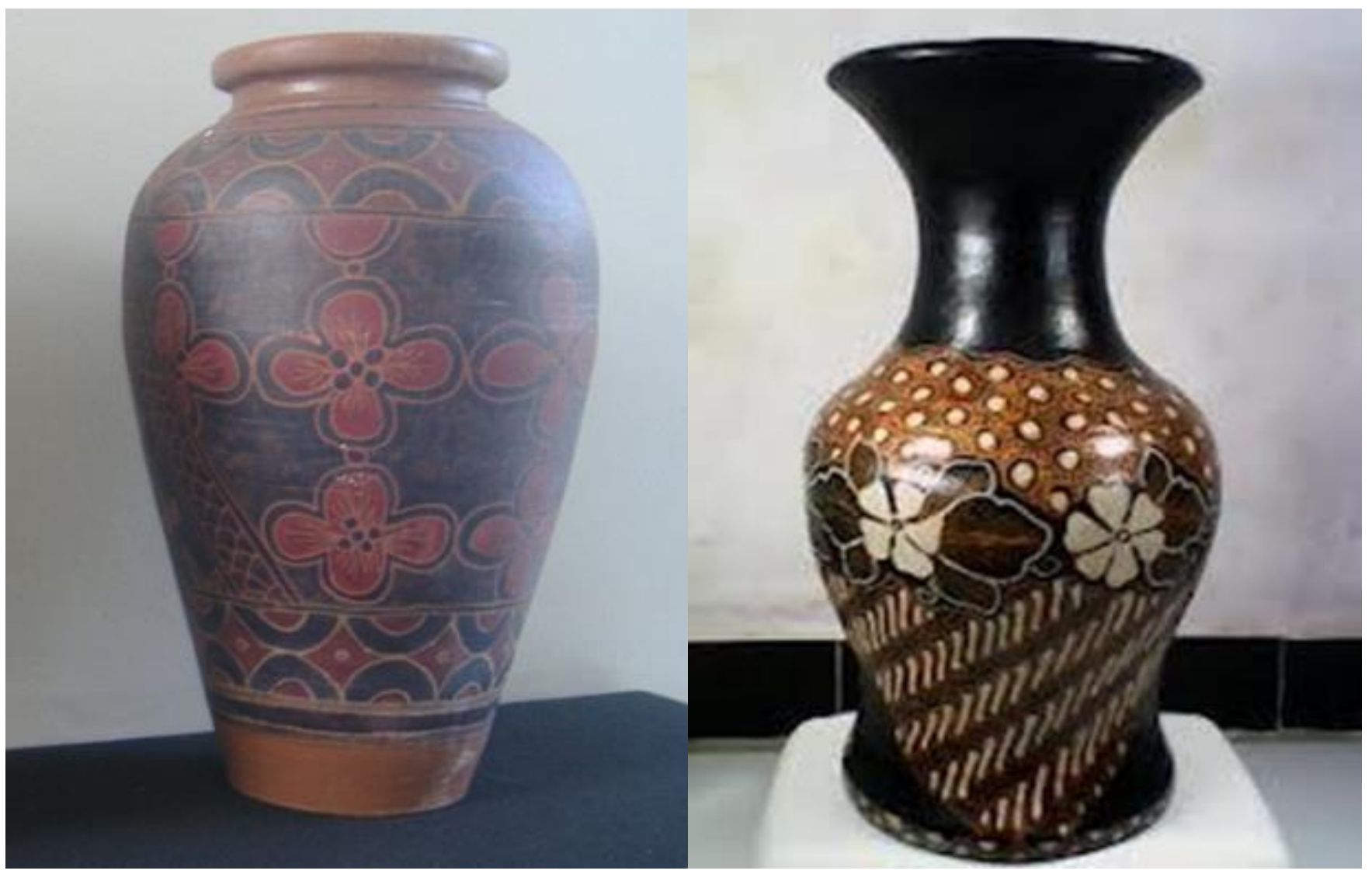

Gambar 2. Produk gerabah dengan perlakuan biasa (kiri) dan produk gerabah setelah dilakukan optimalisasi (kanan (Foto: Edi Eskak, 2014) 
Pelorodan/Pembersihan Lilin. Pelorodan adalah proses pembersihan malam (lilin batik) dengan cara direbus dalam air mendidih $\left(100^{\circ} \mathrm{C}\right)$ sehingga lilin meleleh dan luruh bersama air yang panas.Untuk mempercepat luruhnya lilin dari gerabah serta mencegah lilin kembali lengket dan menempel lagi pada gerabah, air rebusan dapat dicampur dengan soda abu (Na2CO3), dengan perbandingan 1 liter air : 20gr soda abu. Untuk gerabah kecil dapat dengan cara dicelupkan ke dalam air mendidih, untuk gerabah besar dapat dilakukan dengan diguyur atau disemprotkan air panas. Pelorodan satu buah gerabah ukuran sedang, rata-rata memerlukan waktu 12 menit.

Finishing. Finishing merupakan tahapan akhir dalam proses pembuatan suatu produk, dengan cara memberi lapisan cat untuk mempeindah sekaligus mengawetkan karya. Pada produk gerabah batik ini, finishing diakukan dengan memberikan lapisan cat bening pada permukaan gerabah. Pelapisan sebaiknya dilakukan dengan cara disemprotkan, karena dengan cara pelaburan goresan kuas dapat sedikit menghapus warna.

Pengujian ketahanan luntur. Sebagai karya seni yang didedikasikan untuk industri kreatif, produk gerabah batik juga harus memenuhi standar mutu produk dalam perdagangan. Untuk menjamin kualitas tersebut, kehandalan produk yang dihasilkan perlu diuji mutu atau kualitasnya. Pengujian dapat dilakukan sendiri untuk mengetahui kekuatan material atau ketahanan luntur zat warna, dan lain sebagainya. Namun sebaiknya pengujian mutu produk dengan kriteria standar tertentu diujikan ke laboratorium yang terakreditasi milik kantor litbang maupun perguruan tinggi.

\section{Hasil dan pembahasan}

Optimalisasi penerapan teknik batik pada gerabah merupakan usaha untuk mencapai kualitas produk yang lebih baik dengan proses produksi yang lebih ekonomis. Hasil penelitian optimalisasi dekorasi batik pada gerabah ini menunjukkan peningkatan kualitas pewarnaan dan finishing yang berakumulasi pada produk jadi yang lebih bagus. Tabel 1 menunjukkan usaha optimalisasi yang telah dilakukan, Tabel 2 menunjukkan signifikansi peningkatan kualitas produk dari optimalisasi yang dilakukan, sedangkan Tabel 3 menunjukkan hasil uji ketahanan luntur warna yang meningkat. Perbandingan secara visual antara gerabah batik yang diproses dengan cara biasa dibandingkan dengan gerabah batik yang dihasilkan dengan optimalisasi teknik dan bahan, dapat dilihat dalam Gambar 2.

Tabel 1. Permasalahan dan Optimalisasi Yang Dilakukan

\begin{tabular}{|c|c|c|c|}
\hline No & Permasalahan & Solusi/Optimalisasi & Keterangan \\
\hline 1 & $\begin{array}{l}\text { Gerabah berwarna kecoklatan bervariasi } \\
\text { dari muda/cerah sampai tua/kusam. }\end{array}$ & $\begin{array}{l}\text { Pilih gerabah dengan } \\
\text { muda/cerah. }\end{array}$ & $\begin{array}{l}\text { Meningkatkan variasi warna dan kualitas } \\
\text { warna. }\end{array}$ \\
\hline 2 & Permukaan gerabah kasar. & Pilih gerabah dengan permukaan halus. & Menghemat proses pengamplasan \\
\hline 3 & Gerabah cacat retak. & $\begin{array}{l}\text { Sortir, hanya gunakan gerabah dengan } \\
\text { kondisi baik. }\end{array}$ & $\begin{array}{l}\text { Menghindari kerusakan dalam proses } \\
\text { pembatikan, mengurangi resiko gagal } \\
\text { produksi. }\end{array}$ \\
\hline 4 & $\begin{array}{l}\text { Bentuk gerabah menyulitkan penerapan } \\
\text { motif }\end{array}$ & $\begin{array}{l}\text { Penerapan motif mengikuti bentuk } \\
\text { gerabah, memilih motif dengan } \\
\text { gambar-gambar besar dan penggunaan } \\
\text { canting sedang dan besar. }\end{array}$ & $\begin{array}{l}\text { Penyesuaian motif pada media kain yang } \\
\text { fleksibel ke media gerabah yang kaku dan } \\
\text { keras. }\end{array}$ \\
\hline 5 & $\begin{array}{l}\text { Penggunaan kuas lukis untuk pembatikan } \\
\text { cepat rusak. }\end{array}$ & Menggunakan kuas ijuk aren. & $\begin{array}{l}\text { Kuas ijuk aren lebih tahan panas dan kuat } \\
\text { untuk bahan kental lilin panas. }\end{array}$ \\
\hline 6 & $\begin{array}{l}\text { Kesulitan pewarnaan celup pada gerabah } \\
\text { besar. }\end{array}$ & Penerapan teknik pewarnaan coletan. & $\begin{array}{l}\text { Menggunakan warna-warna kuat agar } \\
\text { motif terlihat jelas. }\end{array}$ \\
\hline 8 & $\begin{array}{l}\text { Ketahanan luntur warna remasol } \\
\text { terhadap gosokan kering maupun basah } \\
\text { kurang baik. }\end{array}$ & $\begin{array}{l}\text { Gerabah dikeringkan, kemudian dilapisi } \\
\text { cat transparan tipis. Bila kering baru } \\
\text { dilakukan pelorodan dengan air panas. }\end{array}$ & $\begin{array}{l}\text { Menghindari proses yang merusak } \\
\text { produk, menerapkan proses yang aman. }\end{array}$ \\
\hline 9 & $\begin{array}{l}\text { Lapisan warna batik pada gerabah sangat } \\
\text { tipis dan mudah kusam oleh gosokan, } \\
\text { paparan sinar, dan debu. }\end{array}$ & $\begin{array}{l}\text { Memberi lapisan proteksi dengan } \\
\text { finishing cat transparan. }\end{array}$ & $\begin{array}{l}\text { Lapisan cat transparan berfungsi untuk } \\
\text { memperindah dan melindungi produk, } \\
\text { sekaligus mudah dibersihkan. }\end{array}$ \\
\hline 10 & $\begin{array}{l}\text { Pelapisan akhir dengan kuas maupun kain } \\
\text { perca kaos (kain pop) dapat sedikit } \\
\text { mengikis warna. }\end{array}$ & $\begin{array}{l}\text { Pelapisan menggunakan teknik semprot } \\
\text { menggunakan sprayer dan kompresor. }\end{array}$ & $\begin{array}{l}\text { Sebenarnya bila fiksasi atau penguncian } \\
\text { warna sempurna, warna tidak akan luntur. }\end{array}$ \\
\hline
\end{tabular}


Edi Eskak, Irfaina Rohana Salma, \& Hadi Sumarto

Peningkatan kecerahan dan daya rekat warna pada produk gerabah batik

Tabel 2. Hasil optimalisasi

\begin{tabular}{|c|c|c|c|c|c|c|c|c|}
\hline & \multicolumn{3}{|c|}{ Gerabah Kusam } & \multicolumn{3}{|c|}{ Gerabah Cerah } & \multirow[t]{2}{*}{ Non Coating } & \multirow[t]{2}{*}{ Coating } \\
\hline & Zat warna Naphthol & (Optimalisas & & & & & & \\
\hline No & $\begin{array}{l}\text { Waktu } \\
(3 X)\end{array}$ & $\begin{array}{c}\text { Jumlah } \\
\mathrm{gr} / 2 \mathrm{lt}\end{array}$ & Hasil & $\begin{array}{l}\text { Waktu } \\
\text { (3X) }\end{array}$ & $\begin{array}{l}\text { Jumlah } \\
\text { (gr/ 2lt) }\end{array}$ & Hasil & Hasil & Hasil \\
\hline \multirow[t]{2}{*}{1} & Gerabah Slawi & & & & & & & \\
\hline & $15^{\prime \prime}$ & 20 & Baik & $15^{\prime \prime}$ & 20 & Baik & Baik & Sangat Baik \\
\hline \multirow[t]{2}{*}{2} & Gerabah Bayat/Klate & & & & & & & \\
\hline & $\begin{array}{c}15^{\prime \prime} \\
\text { Gerabah Kasongan }\end{array}$ & 20 & Baik & $15^{\prime \prime}$ & 20 & baik & Baik & Sangat baik \\
\hline \multirow{2}{*}{3} & $15^{\prime \prime}$ & 20 & Cukup Baik & $15^{\prime \prime}$ & 20 & baik & Baik & Sangat Baik \\
\hline & Zat warnaRapid (Op & timalisasi) & & & & & & \\
\hline No & $\begin{array}{l}\text { Waktu } \\
(3 X)\end{array}$ & $\begin{array}{l}\text { Jumlah } \\
\text { (gr/300 cc) }\end{array}$ & Hasil & $\begin{array}{l}\text { Waktu } \\
(3 X)\end{array}$ & $\begin{array}{l}\text { Jumlah } \\
\text { (gr/300 cc) }\end{array}$ & Hasil & Hasil & Hasil \\
\hline 1 & Gerabah Slawi & & & & & & & \\
\hline 2 & $\begin{array}{c}15^{\prime \prime} \\
\text { Gerabah Bayat }\end{array}$ & 15 & Baik & $15^{\prime \prime}$ & 15 & Baik & Baik & Sangat Baik \\
\hline \multirow[t]{3}{*}{3} & $\begin{array}{c}15^{\prime \prime} \\
\text { Gerabah Kasongan }\end{array}$ & 15 & Baik & $15^{\prime \prime}$ & 15 & Baik & Baik & Sangat Baik \\
\hline & $15^{\prime \prime}$ & 15 & Cukup Baik & $15^{\prime \prime}$ & 15 & Baik & Baik & Sangat Baik \\
\hline & Zat warna Remasol & (Optimalisasi & & & & & & \\
\hline No & $\begin{array}{l}\text { Waktu } \\
(3 X)\end{array}$ & $\begin{array}{l}\text { Jumlah } \\
\text { (gr/300 cc) }\end{array}$ & Hasil & $\begin{array}{l}\text { Waktu } \\
\text { (3X) }\end{array}$ & $\begin{array}{l}\text { Jumlah } \\
\text { (gr/300 cc) }\end{array}$ & Hasil & Hasil & Hasil \\
\hline 1 & Gerabah Slawi & & & & & & & \\
\hline 2 & $\begin{array}{c}15^{\prime \prime} \\
\text { Gerabah Bayat }\end{array}$ & 15 & Cukup Baik & $15^{\prime \prime}$ & 15 & Baik & Baik & Sangat Baik \\
\hline 3 & $\begin{array}{c}15^{\prime \prime} \\
\text { Gerabah Kasongan }\end{array}$ & 15 & Cukup Baik & $15^{\prime \prime}$ & 15 & Baik & Baik & Sangat Baik \\
\hline & $15^{\prime \prime}$ & 15 & Cukup Baik & $15^{\prime \prime}$ & 15 & Baik & Baik & Sangat Baik \\
\hline
\end{tabular}

Tabel 3. Hasil uji ketahanan luntur

\begin{tabular}{|c|c|c|c|c|c|c|}
\hline No & Hasil Uji & Naphthol & Rapid & Remasol & Non Coating & Coating \\
\hline \multirow[t]{3}{*}{1} & $\begin{array}{c}\text { Ketahanan luntur warna terhadap : } \\
-\quad \text { Gosokan kering }\end{array}$ & & & & & \\
\hline & - Gosokan basah & $3-4$ & $3-4$ & 3 & $3-4$ & 5 \\
\hline & & $3-4$ & $3-4$ & 3 & $3-4$ & 5 \\
\hline \multirow[t]{2}{*}{2} & $\begin{array}{l}\text { Ketahanan luntur warna terhadap } \\
\text { sinar: terang hari }\end{array}$ & & & & & \\
\hline & - Nilai tahan sinar & 4 & 4 & 4 & 4 & 5 \\
\hline
\end{tabular}

Keterangan:

$1=$ Sangat Jelek

$2=$ Jelek

$3=$ Cukup

$4=$ Baik

$5=$ Sangat Baik

Tabel 3 menunjukkan hasil pengujian terhadap ketahanan luntur warna terhadap gosok dan cahaya matahari. Hasil pengujian ketahanan luntur warna terhadap gosokan kering dan basah memperoleh nilai 3-4, ini berarti cukup baik. Ketahanan luntur warna 
terhadap cahaya terang hari memperoleh angka 4, ini berarti baik.

Ketahanan luntur warna terhadap cahaya terang hari memperoleh angka 4 , ini berarti baik. Ketahanan luntur terhadap warna yang dilapisi cat transparan memperoleh nilai 5, yang berarti sangat baik. Pewarnaan paling baik dengan menggunakan zat warna rapid dan naphthol. Hasil warna lebih cemerlang dengan pemilihan warna asal gerabah cerah atau tidak gelap, serta dilakukan pelapisan akhir cat transparan, seperti terlihat dalam Gambar 2 sebelah kanan. Gambar 2 kiri menunjukkan produk gerabah batik yang belum dilakukan penelitian optimalisasi ini.

Pengujian ketahan luntur warna terhadap gosokan dan sinar terang hari pada produk gerabah batik ini dilakukan di Laboratorium Uji Kalibrasi Industri Kerajinan dan Batik (LUK-IKB) Balai Besar Kerajinan dan Batik (BBKB) yang beralamat di Jalan Kusumanegara 7, Yogyakarta.

Metode uji ketahanan luntur warna terhadap gosokan kapas kering dan basah menggunakan SNI 080288-1989. Metode uji ketahanan luntur warna terhadap cahaya terang hari atau nilai tahan sinar menggunakan SNI 08-0289-1996.

\section{Kelayakan Penerapan Pada IKM}

Hasil penelitian ini layak diterapkan pada IKM karena merupakan teknologi sederhana namun tepat guna yang berbasis pada budaya. Penerapan teknik batik pada gerabah akan menambah keanekaragaman produkgerabah yang indah. Keindahan pada produk akan meningkatkan daya tarik konsumen, dan nilai tambah produk.

Dilihat dari aspek ekonomi harga produk gerabah batik layak untuk diterapkan di IKM sebagai pembuatan produk yang menguntungkan. Sebagai ilustrasi perhitungan ekonomisnya dapat dicermati berikut ini. Dewasa ini harga 1 produk gerabah matang polosan antara Rp 20.000 - Rp 25.000 dengan tinggi $60-70 \mathrm{~cm}, \varnothing 20-30 \mathrm{~cm}$. Harga jual produsen untuk satu buah produk gerabah tersebut yang sudah finishing laminasi kulit telur, pasir, cat, anyam dapat mencapai harga antara Rp 120.000 - Rp 150.000. Berpedoman pada harga tersebut, maka produk gerabah batik dapat mempunyai harga dasar atau harga produsen yang sangat kompetitif. Sebagai gambaran hal tersebut dapat dilihat dalam perhitungan berikut ini.

$$
\begin{array}{ll}
\text { Gerabah polosan } & \text { Rp } 25.000 \\
\text { Ongkos proses batik } & \underline{R p ~ 60.000+} \\
& \text { Rp } 85.000
\end{array}
$$
Harga produsen
$\underline{\mathrm{Rp} 25.000+}$
Rp 110.000

Penjelasan di atas menunjukkan bahwa gerabah batik mempunyai kelayakan untuk diterapkan pada IKM. Penerapan teknik dekorasi batik pada gerabah juga merupakan terobosan yang cukup bagus untuk diterapkan di berbagai daerah, dengan mengangkat keunikan daerah masing-masing sebagai ciri khas motif batik gerabahnya.

\section{Kesimpulan}

Optimalisasi pembuatan dekorasi batik pada gerabah telah dilakukan dan berhasil meningkatkan kualitas warna yang lebih baik dari penelitian sebelumnya. Pengujian dilakukan terhadap ketahanan luntur warna batik gerabah. Hasil pengujian ketahanan luntur warna terhadap gosokan kering dan basah memperoleh nilai 3-4, ini berarti cukup baik. Ketahanan luntur warna terhadap cahaya terang hari memperoleh angka 4, ini berarti baik. Ketahanan tersebut terhadap batik gerabah yang belum dilapisi cat transparan atau non coating. Ketahanan luntur terhadap warna yang telah dilapisi cat transparan (coating) memperoleh nilai 5, yang berarti sangat baik. Pewarnaan paling baik dengan menggunakan zat warna rapid dan naphthol. Hasil warna lebih cemerlang bila pemilihan gerabah dengan warna asal yang muda atau cerah. Dekorasi hasil pembatikan tersebut sebaiknya diberi pelapisan akhir cat transparan.

Sebagai saran, pada tahap berikutnya, perlu dilakukan penelitian pembuatan gerabah dengan hasil pembakaran biskuit berwarna putih, sehingga gerabah dapat dieksplorasi dengan warna-warna dalam komposisi warna yang lebih kaya. Perlu juga dilakukan alih teknologi pembatikan gerabah ini ke berbagai daerah di seluruh Nusantara, sehingga kemajuan industri kreatif tidak hanya terpusat di Jawa dan Bali saja.

Penelitian ini terlaksana atas bantuan berbagai pihak. Untuk itu, penulis merasa perlu berterima kasih kepada pihak-pihak tersebut, diantaranya Ir. Sardjono, Kepala Balai Besar Kerajinan dan Batik (BBKB), Ir. Endang Pristiwati, M.Si, Kabid Sarana Riset dan Standardisasi, Sujanarto, SE, Kabid Peningkatan Kompetensi dan Alih Teknologi, perajin gerabah Kasongan, pengrajin gerabah Slawi, pengrajin gerabah Bayat Klaten, Studio Edistone Yogyakarta, dan beberapa pihak yang telah banyak membantu dalam litbang ini.

Keuntungan $30 \%$ x $\quad$ Rp 85.000 
Edi Eskak, Irfaina Rohana Salma, \& Hadi Sumarto

Peningkatan kecerahan dan daya rekat warna pada produk gerabah batik

\section{Daftar pustaka}

Astuti, A. (2008) Keramik, Ilmu dan Proses Pembuatannya, Yogyakarta:Arindo Nusa Media.

Eskak, E. (2013) Mendorong Kreativitas dan Cinta Batik Pada Generasi Muda. Jurnal Dinamika Kerajinan dan Batik, 30 (1)

Rosari, R. W. (2013) Kamus Seni Budaya. Surakarta: Aksara Sinergi Media

Sumarto, H. Arifin, A. Anwar, N. Subagya. Dahlan. Suwarno dan Siswanto. (2010) Teknologi Pembatikan Pada Gerabah. Laporan Penelitian. Yogyakarta: Balai Besar Kerajinan dan Batik

Suminto, S. (2015) Melirik Ciri Khas Batik Lasem. Productum: Jurnal Desain Produk 1 (1) pp. 22-30 